\title{
Gestão ambiental de parques urbanos: o caso do Parque Ecológico do Município de Belém Gunnar Vingren
}

\author{
Environmental management of urban parks: the case of the Gunnar Vingren \\ Ecological Park in Belem, Para state, Brazil
}

Silvia Laura Costa Cardoso ${ }^{[a]}$, Mário Vasconcellos Sobrinho ${ }^{[b, c]}$, Ana Maria de Albuquerque Vasconcellos ${ }^{[c]}$

[a] Universidade Federal do Pará (UFPA), Programa de Pós-Graduação em Desenvolvimento Sustentável do Trópico Úmido, Belém, PA, Brasil

[b] Universidade Federal do Pará (UFPA), Programa de Pós-Graduação em Gestão dos Recursos Naturais e Desenvolvimento Local na Amazônia, Belém, PA, Brasil

[c] Universidade da Amazônia (Unama), Programa de Pós-Graduação em Administração, Belém, PA, Brasil

\section{Resumo}

0 artigo debate fatores que facilitam e dificultam a implementação de um parque urbano. Discutem-se as facilidades e dificuldades inerentes à implementação de parques urbanos face aos múltiplos interesses que envolvem os atores sociais. Analisa-se o caso do Parque Ecológico do Município de Belém Gunnar Vingren (PEGV) e enfocam-se os conceitos de participação, governança urbana e gestão ambiental. Utiliza-se da teoria dos stakeholders para identificação dos atores sociais e interpretação de seus comportamentos no processo de implementação do parque. Metodologicamente, o trabalho assume a abordagem qualitativa e se utiliza da observação direta e entrevistas semiestruturadas. 0 estudo mostra a importância dos movimentos sociais urbanos para a preservação das áreas verdes da cidade e melhoria da qualidade de vida urbana. Aponta que a gestão ambiental dos parques urbanos depende fundamentalmente do ordenamento do seu próprio território e entorno. Em áreas com território desordenado é elevada a possibilidade de pressão sobre parque e depredação dos seus recursos naturais. A pesquisa mostra que os modelos de gestão urbana da cidade influenciam no nível de participação dos atores sociais nos conselhos gestores de parques. Empiricamente, o artigo mostra que a capacidade institucional para a gestão do PEGV avançou bastante; todavia, paradoxalmente, a capacidade organizacional do governo municipal é limitada para a gestão de todo o sistema. Dentre todos os desafios na gestão de parques urbanos, o mais proeminente é o de construção de uma aliança de governança participativa entre os stakeholders.

Palavras-chave: Parque urbano. Governança ambiental. Gestão ambiental.

SLCC é Turismóloga, administradora, mestre em Gestão dos Recursos Naturais e Desenvolvimento Local na Amazônia, doutoranda em Ciências: Desenvolvimento Socioambiental, e-mail: silvialaura19@gmail.com

MVS é Economista, doutor em Estudos do Desenvolvimento, e-mail: mariovasc@ufpa.br; mariovasc@unama.br

AMAV é Cientista social, doutora em Estudos do Desenvolvimento, e-mail: annavasc@unama.br 


\section{Abstract}

This paper addresses the factors that facilitate and hamper the implementation of urban parks. It discusses the advantages and difficulties inherent to the implementation of urban parks, taking into account the multiple interests involving social actors. The present study analyzes the case of the Gunnar Vingren Ecological Park in Belem, Para state, Brazil, and focuses on the concepts of participation, urban governance and environmental management. It uses the stakeholder theory to identify social actors and understand their behavior in the implementation process of the park. Methodologically, the research was based on qualitative approach and used direct observation and semi-structured interviews for data collection. It shows the importance of urban social movements to preserve the green areas of the city and improve urban life quality. It indicates that the environmental management of urban parks depends fundamentally on the spatial planning of their inner areas and surroundings. It shows that, in areas with disordered territory, there is high possibility of pressure on the park and depredation of its natural resources. The study also shows that urban management patterns influence the level of participation of social actors in the management committees of parks. Empirically, this paper shows a great progress in the institutional capacity for the management of the Gunnar Vingren Park; however, paradoxically, the municipal government organizational capacity is limited to manage the whole system. The most significant challenge in managing urban parks is to develop a participatory governance alliance between stakeholders.

Keywords: Urban park. Environmental governance. Environmental management.

\section{Introdução}

Ao percorrer a história da criação dos parques urbanos, percebe-se que o mesmo é um produto da era industrial (Lima \& Rocha, 2009). As primeiras demandas por espaços naturais voltados para o lazer e para a recreação surgiram em decorrência do processo de urbanização das cidades, aglomeração demográfica nos centros urbanos e crescimento maciço da atividade industrial (Vainer, 2010). Com o crescimento das cidades e a destruição das florestas, o interesse por jardins e parques apareceu como contraponto à sociedade industrial (Ferreira, 2006). 0 parque urbano nasceu sob a concepção de dotar as cidades de espaços adequados para atender a nova demanda social: o lazer e o tempo do ócio, contrapondo-se ao ambiente urbano de vida agitada. A criação dos espaços verdes destinava-se especialmente à promoção da qualidade de vida urbana no bem-estar das pessoas (Silva, 2003a). Sob essa concepção foi que nasceram os parques urbanos no Brasil e que os alicerçaram até o final dos anos 90.

Com a criação da Lei n. 9.985 (SNUC) em 2000, o parque urbano no Brasil assume novo significado e função: preservação da biodiversidade para o bem coletivo. 0 parque urbano passa a ser o locus da preservação ambiental, da contemplação e do bem-estar daqueles que o utilizam e/ou que vivem ao redor do parque.

Sob a perspectiva do bem coletivo, a lei do SNUC traz no seu bojo a necessidade de democratização na criação e gestão do espaço público envolvendo a participação da sociedade civil na sua gestão. Todavia, a participação dos atores urbanos não acontece de forma consensual. Os atores possuem diferentes interesses e em consequência disputam o domínio e a influência sobre a gestão dos parques urbanos.

O objetivo deste artigo é analisar os interesses dos atores sociais diante da implementação de um parque urbano, especificamente do Parque Ecológico do Município de Belém Gunnar Vingren (PEGV). Busca-se entender quais fatores facilitam e dificultam a implementação de um parque urbano. Tem-se como problema do estudo a compreensão sobre as ações, contradições, facilidades e dificuldades inerentes à gestão do parque urbano e os fatores que influenciam sua governança, o que denominamos de governança ambiental.

Trata-se de um estudo de caso com abordagem qualitativa que, em termos teóricos, envolveu a discussão sobre a participação e governança de parques urbanos. Os dados primários foram obtidos entre setembro de 2011 e janeiro de 2012 por meio de pesquisa documental e pesquisa de campo 
que envolveu visitas ao PEGV e área do entorno. Utilizou-se da observação direta e de 12 entrevistas semiestruturadas, sendo 4 com agentes do Estado e do município de Belém, 4 com representantes do Conselho Gestor do PEGV, 3 com moradores dos conjuntos habitacionais de seu entorno (Médici e Bela Vista) e 1 com o diretor da instituição pública de ensino que realiza visita no parque. Estes foram escolhidos por serem ativos atores no processo de gestão do parque e que são, coincidentemente, membros do Conselho Gestor do parque. As entrevistas foram transcritas de modo que fossem examinadas à luz da análise de conteúdo de três importantes tópicos inter-relacionados: gestão do parque, participação dos atores sociais locais na gestão do parque e percepção do entrevistado em relação à importância do PEGV no contexto urbano. Destaque-se que o período temporal de informações e dados levantados foi de 1991, ano de criação oficial do PEGV, a 2012, período do encerramento da pesquisa. Reporta-se a anos anteriores ao recorte temporal, entretanto, quando há referências importantes a serem destacadas.

O artigo utiliza os conceitos de participação, governança e governança urbana. Para interpretação do comportamento dos atores urbanos, utilizaram-se alguns elementos da teoria dos stakeholders. Esses elementos permitiram entender as convergências e divergências nas formas de pensar e agir dos diversos atores que se relacionam com o processo de gestão ambiental do PEGV.

O artigo está estruturado em quatro seções, além da introdução e considerações finais. A primeira seção discute as diferentes acepções acerca da definição de parques urbanos. A segunda seção se direciona para apresentação do Parque Ecológico do Município de Belém Gunnar Vingren (PEGV) e todas as circunstâncias que o levam a ser fonte de pressão urbana. A terceira seção aborda os divergentes modelos de governança ambiental implantados na cidade nos períodos de 1997 a 2004 e, posteriormente, 2005 a 2012 de modo a compreender a conformação dos diferentes interesses dos atores sociais. A última seção identifica as convergências e divergências de interesses entre esses atores com destaque para a intervenção dos projetos governamentais que contribuíram para a degradação ambiental do parque. Nesta seção abordam-se as ações, contradições, facilidades e dificuldades inerentes à implementação da governança ambiental do Parque Ecológico do Município de Belém Gunnar Vingren (PEGV).

\section{Significando parques urbanos}

Os parques urbanos desempenham diferentes funcionalidades e configurações nas cidades, os quais estão diretamente relacionados às formas de gestão ambiental e padrões de crescimento dos núcleos urbanos. Enquanto alguns centros recebem multidões, outros estão vinculados à proteção ambiental. Um consenso na literatura, entretanto, é que parques urbanos são estrategicamente importantes para a qualidade de vida das pessoas no conjunto das sociedades em crescente urbanização (Chiesura, 2004; Kaplan, 1983; Ulrich, 1984). Isso porque os parques urbanos prestam serviços ambientais à população por meio da filtragem do ar, água, vento e poluição sonora; estabilização do microclima (Tratalos et al., 2007); formação de um meio ambiente natural que influencia na saúde mental das pessoas por via da redução do estresse e provisão de sensação de paz e tranquilidade (Chiesura, 2004) e, ainda, de espaço para promoção da saúde física (Mccormack et al., 2010). Todos esses benefícios creditados aos parques urbanos vinculam-se às perspectivas analíticas da concepção de cidade sustentável (Loures et al., 2007). Portanto, elaborar estudos sobre parques urbanos implica, primeiramente, considerar a acepção do que seja parque, considerando as diferenças de dimensões, formas de tratamento, funções e equipamentos (Scalise, 2002).

Na Lei n. 9.985/00, do Sistema Nacional de Unidades de Conservação (SNUC), a definição de parque está relacionada ao conceito de Unidades de Conservação (UC) de proteção integral, seja em perímetro urbano ou rural, seja de gestão federal, estadual ou municipal. A criação desses parques tem a proposição de preservar o meio ambiente e a qualidade de vida das populações que habitam no entorno dessas áreas (Brasil, 2000).

Contudo, não há um consenso entre os autores a despeito da definição do termo parque, configurando uma confusão conceitual que o torna próximo de outros espaços livres de lazer como a praça e o jardim (Kliass, 1993; Scalise, 2002; Lau, 2008). Kliass (1993), por exemplo, define parques urbanos como "espaços públicos com dimensões significativas e predominância de elementos naturais, 
principalmente, de cobertura vegetal, destinados à recreação". Scalise (2002), por sua vez, reportando-se a Olmsted, o criador do Central Park de Nova York, conceitua parques como "lugares com amplitude e espaço suficientes e com todas as qualidades necessárias que justifiquem a aplicação a eles daquilo que pode ser encontrado na definição do termo cenário ou da palavra paisagem" (Scalise, 2002). Para Faria (1998), os parques urbanos podem funcionar como vetor de sustentabilidade urbana se tiverem sua função ecológica equilibrada (Faria, 1998). Neste prisma, a implementação de parques urbanos constitui papel essencial na busca do equilíbrio ecológico da cidade (Lau, 2008).

Assim, infere-se que a definição de parque e sua funcionalidade é diversificada na medida em que a sociedade se transforma ao longo dos anos. Então, é necessário cautela, sobretudo, para não reduzir o significado das inúmeras acepções de parque ao senso comum, ou seja, um espaço destinado ao lazer que se confunde com a praça e o jardim. Sobre esse mesmo aspecto, Terra (2000) comenta que os termos jardim, praças e parque possuem o mesmo significado de áreas verdes e somente se diferenciam pelas funções e tamanho da área (Terra, 2000; Macedo \& Sakata, 2002; Silva, 2003b). De fato, há uma extensa variedade de significados de parques urbanos. Tais definições estão diretamente relacionadas com a ideia da funcionalidade desses espaços e seus desdobramentos no ambiente urbano.

Neste artigo, parque urbano significa espaço público de socialização e aprendizado. Em consonância com o SNUC, que rege as diretrizes para o uso de uma UC na legislação ambiental brasileira, seu uso deve ser restrito pelos atores sociais, sendo admitida apenas a permissão de uso público em espaços destinados às atividades de educação e interpretação ambiental, uso lúdico e cultural com fins de preservação dos recursos naturais no ambiente urbano.

\section{O Parque Ecológico do Município de Belém Gunnar Vingren (PEGV): criação, intervenção e degradação}

O Parque Ecológico do Município de Belém Gunnar Vingren (PEGV) ${ }^{1}$ é um fragmento de floresta

\footnotetext{
1 Quando de sua constituição, foi denominado inicialmente de Parque Ecológico do Município de Belém.
}

primária da cidade de Belém, estado do Pará, que assume um significado de Unidade de Conservação (UC) de uso integral a partir da lei municipal que o cria. Localiza-se entre os bairros de Val-de-Cans e Marambaia, e foi criado pela Lei Municipal n. 7.539 de 19 de novembro de 1991, com uma área de 35 hectares. O PEGV enquanto UC municipal, segundo a referida lei, tem como finalidade a preservação, manutenção e restauração da área verde. Destaquese que o PEGV ainda não faz parte do SNUC, embora o governo municipal esteja se organizando para esse requerimento. Essa organização perpassa pelo processo de regularização fundiária de toda a área que inclui o parque e seu entorno. 0 parque é contíguo a outras áreas verdes urbanas, mais precisamente de áreas militares (uma área da Marinha e outra área da Aeronáutica) formando um mosaico de áreas verdes urbanas sem acesso público. A gestão do PEGV é realizada pela Prefeitura Municipal de Belém, através da Secretaria Municipal de Meio Ambiente (SEMMA), todavia seguindo as diretrizes de um conselho gestor criado para tal fim. O Conselho Gestor do PEGV foi estatuído pela portaria municipal n. 110 de 29/9/2010 (Belém, 2010) e é formado por representantes de 20 entidades, sendo 10 advindas da sociedade civil e 10 do poder público. Dentre as entidades da sociedade civil está a Associação dos Moradores dos Conjuntos Presidente Médici I e II (AMME), representante inicial dos moradores do seu entorno. De fato, a história de criação do PEGV está vinculada aos movimentos sociais dos moradores dos Conjuntos Presidente Médici I e II que demandaram ao poder público municipal a proteção da floresta primária que passou a sofrer invasão e depredação a partir do final da década de 1980 (Cardoso, 2012). Segundo entrevistas obtidas na AMME, 35 ha que hoje pertencem ao PEGV eram de propriedade dos conjuntos habitacionais. Eis o porquê, de alguma forma, a AMME participar da gestão do parque desde sua criação quando passou a ser entidade membro da Comissão de Defesa do Meio Ambiente do município de Belém, comissão esta estabelecida pelo art. 158 da Lei Orgânica do Município de Belém (Belém, 1991).

A segurança e a fiscalização do PEGV são realizadas pela Guarda Municipal de Belém (GBEL). Estas consistem em coibir a prática de caça, retirada de frutos, degradação ambiental e acesso de invasores no interior do parque. 
Seis anos após a sua criação em 1991, o PEGV sofreu alto impacto de dois significativos projetos governamentais: o projeto da macrodrenagem da bacia do Una, em 1998, e o projeto de extensão da avenida centenário (Projeto Ação Metrópole), em 2010, o primeiro de projeção municipal e o segundo de integração metropolitana e, portanto, de nível estadual. Esses projetos, apesar de se direcionarem para o desenvolvimento urbano de Belém e região metropolitana (como o caso do Projeto da Macrodrenagem que tinha como objetivo diminuir as áreas alagadas denominadas "baixadas da cidade"), contribuíram para o aumento da pressão sobre a área verde, desta feita já oficialmente consubstanciada enquanto parque urbano municipal. A pressão sobre o PEGV se caracteriza pela ocupação desordenada no seu entorno, insegurança no circuito do parque, crescente especulação imobiliária e processo de degradação ambiental da área protegida. Esse cenário é observado nos estudos de Belém (2000); Silva (2008) e Dias (2010) e corroborado nas entrevistas realizadas com os atores sociais que se relacionam com o parque.

De fato, as ações antrópicas que contribuíram ao longo dos anos para a degradação ambiental do PEGV tiveram início a partir da integração do sistema viário central ao da área de expansão da cidade de Belém, em 1992, quando foram abertas duas vias marginais ao longo de um canal existente denominado São Joaquim. Essa obra provocou a perda de aproximadamente 7 ha de mata ciliar dentro dos limites do parque (Belém, 2000).

Esse cenário se agravou ainda mais ao longo de 1998, período em que houve a implantação do "projeto de saneamento para recuperação das baixadas de Belém - macrodrenagem da bacia do Una" (Projeto da Macrodrenagem) ${ }^{2}$, sob a responsabilidade da Prefeitura Municipal de Belém (PMB), por via da Secretaria Municipal de Saneamento (SESAN). O projeto objetivou intervir na bacia do Una e eliminar o alagamento em uma das áreas prioritárias, denominadas "baixadas de Belém", em consonância com o Plano de Desenvolvimento da Região Metropolitana de Belém (PDRMB). 0 projeto

\footnotetext{
$\overline{2}$ A bacia do Una abrange parcial ou totalmente parte significativa dos bairros de Belém, tais como: São Brás, Umarizal, Marco, Barreiro, Fátima, Pedreira, Telégrafo, Sacramenta, Miramar, Marambaia, Souza, Benguí, Maracangalha, Val-de-Cans e Mangueirão (Belém, 1999).
}

buscou resolver graves problemas de inundações que ocorriam em grande parte da cidade em função do transbordamento das águas da bacia do Una, conciliando com obras de infraestrutura de saneamento básico e sistema viário para o conjunto da região metropolitana (Belém, 1992).

A partir dessa intervenção governamental, a comunidade do entorno do parque, por via da Associação dos Moradores dos Conjuntos Presidente Médici I e II (AMME), se mobilizou novamente contra os movimentos de invasão, desta feita através de ação judicial, inviabilizando a implantação de esgoto sanitário na área do parque e a degradação ambiental provocada pelo Projeto da Macrodrenagem. Essa mobilização conseguiu neutralizar algumas ações de impacto ambiental no PEGV, tanto advindas da obra do governo municipal quanto dos processos de invasão, embora não tenha conseguido eliminar sua degradação. Nesse aspecto, os trechos da entrevista realizada com um morador que reside no Conjunto Presidente Médici II há 30 anos ilustram como a comunidade local se mobilizou, inicialmente para criação do parque e, posteriormente, para contestar os novos movimentos de invasão. Os trechos mostram, também, como a comunidade local via a intervenção e a ação do governo municipal perante a questão da invasão do parque:

Em 31/7/1988, ocorreu a primeira tentativa de invasão na área do parque [...] aí a comunidade preocupada em preservar a área verde se organizou para pedir apoio do governo para que fizesse alguma coisa para proteger a área dos vândalos. Fizemos um abaixo-assinado entre os moradores do Conjunto Médici e enviamos para a Câmara Municipal de Belém para a criação do parque. Esse abaixo-assinado foi de iniciativa dos próprios moradores que queriam alertar as autoridades para discutir a importância de preservar a área verde existente em Belém. [...] o governo é omisso quanto a questão da Invasão Água Cristal que degrada a área verde que buscamos preservar não só para os moradores do Conjunto Médici, mas para a cidade de Belém. Falta empenho do governo 
em querer fazer o parque funcionar de verdade $[\ldots]^{3}$.

Há um reconhecimento do poder público municipal de que o Projeto da Macrodrenagem favoreceu os processos de degradação ambiental no parque e na área de seu entorno. Um dos problemas recentes apontados pelo gestor do PEGV passou a ser as invasões decorrentes da implantação dos projetos advindos do governo estadual que visam a estruturação urbana, agora representado pelo Projeto Ação Metrópole, subprojeto de extensão da Avenida Centenário:

O Projeto Ação Metrópole, sob a responsabilidade do governo do Estado do Pará, gerenciado pela Secretaria de Projetos Estratégicos (SEPE), contemplava ações de urbanização, gestão e integração metropolitana por meio da construção e pavimentação de vias de integração entre os municípios que compõem a região metropolitana. Dentre estas, tem-se uma grande avenida que passou a ser denominada Centenário (Pará, 2010). A Avenida Centenário foi projetada para integrar os municípios de Belém e Ananindeua e, para tal, entrecorta o PEGV dividindo-o em duas partes (Figura 1).

Em 2011, com a entrega da obra da Avenida Centenário, todo o trecho que entrecorta o parque passou a ser coordenado pelo Núcleo de Gestão de Transporte Metropolitano (NGTM), o que significou que uma grande parte da área do PEGV deixou de ser gerida por órgãos ambientais para ser administrada pela agência de trânsito.

As medidas de compensação da perda da biodiversidade ocorrida pela intervenção do Projeto Ação Metrópole foram que condicionaram a liberação da licença ambiental para a intervenção no parque e a instalação da obra da avenida. Esta se deu por via de um termo de compromisso firmado entre a SEPE e SEMMA, a fim de compensar os impactos causados pelo referido projeto (Pará, 2010). As obras de compensação no PEGV via Projeto Ação Metrópole foram finalizadas em 30 de setembro de 2010, data em que o local foi reinaugurado. Ressalte-se que dentre as medidas de compensação ambiental, firmada através do termo de compromisso entre os entes, havia a construção de equipamentos de

\footnotetext{
3 Membro da SOPREN no Conselho Gestor do PEGV e ex-presidente da AMME. Entrevista realizada em jan. 2012.
}

infraestrutura os quais foram construídos com a perspectiva de possibilitar o uso público do parque.

Porém, no que concerne ao acesso público à área verde, identificou-se nas entrevistas que o PEGV tem entrada restrita. A gestão do parque possui como norma que as visitas das instituições estejam condicionadas a um pré-agendamento, tendo em vista que há reduzido quadro técnico, incipiente segurança, inexistência de equipamentos e de projetos direcionados à preservação da área verde ${ }^{4}$. As visitas passaram a ser realizadas de maneira esporádica, sobretudo por alunos de escolas públicas de ensino fundamental dos bairros do entorno do parque, o que acaba por desfigurar a própria concepção de parque enquanto unidade de uso coletivo e acesso irrestrito.

Na verdade, a restrição de uso coletivo do PEGV está vinculada aos resultados da desestruturação do meio ambiente físico e da ocupação desordenada ocorrida dentro e em suas adjacências, pois estas ocasionaram diversos problemas socioambientais que precisam ser solucionados antes de sua total abertura ao público, dentre os quais: a vulneralibilidade dos visitantes e moradores do entorno devido à elevação do número de assaltos e da criminalidade na área; aumento na produção de lixo; e aumento da poluição do canal São Joaquim.

\section{A governança urbana em Belém e seus diferentes modelos}

A abordagem de Broch et al. (2000) considera como governança a estrutura composta de atores sociais e os procedimentos utilizados em processos de tomada de decisão. Os autores se referem às capacidades de ações coletivas - públicas, sociais e privadas existentes e as necessárias para promover a transição na direção da sustentabilidade e advogam que o verdadeiro desenvolvimento não será atingido sem que haja a participação consciente e organizada da sociedade civil (Broch et al., 2000).

Rodrigues \& Malo (2006), ao abordar a teoria dos stakeholders, mencionam que o termo governança é um composto de práticas para que a organização responda aos interesses de vários atores sociais e não de apenas um único grupo. Na perspectiva

\footnotetext{
4 Gestor do PEGV e presidente do Conselho Consultivo do PEGV. Entrevista realizada em set. 2011.
} 


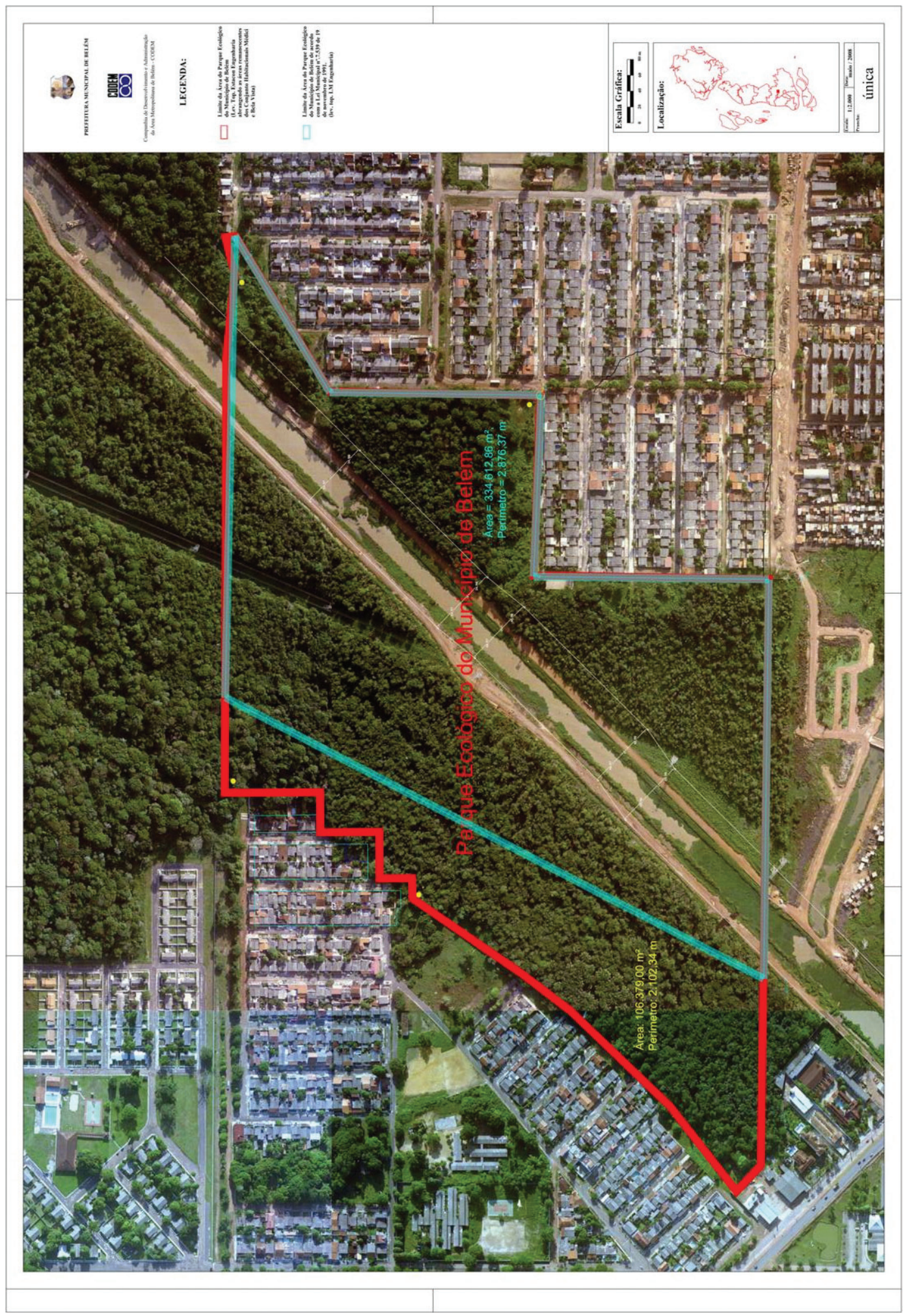

Figura 1 - Limite da área do parque ecológico do município de Belém (PEGV) 5 Fonte: CODEM, 2012.

5 Os documentos oficiais da CODEM apresentam uma diferença no tamanho do PEGV (33,46 ha) em relação ao que consta na Lei nº 7.539 de 19/11/1991 (35 ha).

urbe. Revista Brasileira de Gestão Urbana (Brazilian Journal of Urban Management), 2015 jan./abr., 7(1), 74-90 
democrática, governança é o ato de estabelecer práticas que representem os interesses de um ou mais grupos que integram a organização e os quais esta se disponibiliza a atender (Rodrigues \& Malo, 2006). Contudo, organizações que possuem processos decisórios de natureza coletiva carecem de mecanismos que proporcionem transparência e promovam a emancipação e o "empoderamento" das partes interessadas (Rocha \& Feitosa, 2012).

No âmbito urbano, a governança resulta na desconcentração do Estado nas ações pertinentes à esfera municipal que, entre outras, engloba o processo de descentralização das políticas públicas prevista na Constituição Federal de 1988. Envolve, também, a articulação e coordenação dessas políticas públicas entre órgãos governamentais e destes com instituições sociais. Em outros termos, governança envolve mudanças na consecução de políticas públicas urbanas até então centradas em entidades municipais para uma gestão compartilhada com outros atores sociais sob a perspectiva da nova administração pública - new public management (NPM). O Estado é interpretado como apenas um ator dentre os demais atores elaboradores das políticas públicas e principal responsável pelo bem-estar das coletividades urbanas (Vasconcellos \& Aranha, 2009a). Assim, a governança urbana são ações interrelacionadas e coordenadas entre atores do Estado e sociedade civil na busca de tornar a ação pública mais eficiente e efetiva (Evans, 1997; Tendler, 1997).

Sob o enfoque da governança urbana, a gestão do prefeito Edmilson Rodrigues (1997-2004) foi caracterizada como democrático-participativa (Farias, 2004). Entre 1997 e 2004 foi adotado o princípio de gestão socialmente construída, princípio este implementado em oposição ao modelo burocrático-centralizador até então predominante na história de gestão da cidade de Belém (Farias, 2004).

0 modelo de gestão democrático-participativo liderado pelo prefeito Edmilson Rodrigues iniciou com o orçamento participativo, conferências e fóruns sobre políticas públicas e comissões de fiscalização e controle social (COFIS), embora essas três vertentes não tenham se desenvolvido harmoniosamente entre si durante o governo estabelecido. Segundo Vasconcellos et al. (2009b), isto ocorria porque a estratégia constituída pensava a cidade de maneira desarticulada e pontual do conjunto dos problemas urbanos. Entre 2001 e 2004 a governança da cidade passou a ser realizada pelo Congresso da Cidade, instrumento mais avançado de participação utilizado no governo democrático-participativo. Embora a concepção inicial do modelo tenha acontecido em Porto Alegre, a experiência em implantá-lo ocorreu em Belém, pois o governo local na época oportunizou a participação popular através das plenárias setoriais. A iniciativa favorecia a elaboração de planos antes considerados burocráticos e formais, sobretudo, os planos plurianuais, leis e diretrizes orçamentárias e planos de governo. A experiência do Congresso da Cidade objetivava planejar a cidade como uma só entidade, diferentemente do orçamento participativo que era apenas um dos instrumentos desse planejamento (Vasconcellos \& Aranha, 2009a). No contexto desse planejamento estava a gestão dos parques urbanos.

Durante a execução do Projeto da Macrodrenagem, em 1998, o modelo de gestão ambiental implantado na cidade invocava a interação dos fatores relacionados aos recursos naturais, saneamento, habitação, turismo, educação, economia e transporte. 0 modelo de gestão implantado favorecia o diálogo e a comunicação entre o Estado e a sociedade civil. A participação dos diferentes atores sociais por meio do planejamento participativo e integrado, enquanto instrumento de gestão, possibilitava a abordagem sistêmica e dinâmica da cidade, considerando as peculiaridades locais, aliadas à realidade global (Maia, 2009). O poder local naquele período fomentou esse processo criando diversos canais de participação popular e consolidando os canais já existentes.

Assim, a prática da gestão ambiental do período configurava-se como importante mecanismo de estabelecimento de relações harmônicas entre a sociedade e os agentes gestores do meio ambiente como um todo e dos parques urbanos, em particular. A gestão ambiental assumiu o significado de ser um caminho para a participação de diferentes atores, saberes, usos de técnicas e instrumentos próprios de determinada coletividade local (Dias, 2010).

Com a mudança na administração municipal, a partir de 2005, houve uma ruptura desses instrumentos de gestão, pois a participação dos diferentes atores urbanos, que na gestão anterior era estimulada pela participação popular, cessou. O governo municipal, no período de 2005 a 2012, passou a administrar de forma divergente da gestão 
anterior e conduziu a gestão da cidade de forma centralizada e de forma top down, ou seja, ações norteadas pelo poder normativo, representado pela institucionalização e sanção de políticas públicas, leis, decretos, programas, projetos e conselhos gestores.

Apesar de se alicerçar em modelo burocráticocentralizador, a gestão municipal de 2005 a 2012 foi que instituiu a Política Municipal de Meio Ambiente e o Sistema Municipal de Meio Ambiente (SISEMMA), por via da Lei n. 8.489, de 29 de dezembro de 2005. Estes passaram a ser os instrumentos norteadores da gestão ambiental do município de Belém. A referida lei traz em seu bojo os princípios, objetivos e diretrizes do planejamento e da gestão ambiental da cidade. A Lei n. 8.489 instituiu, ainda, o Fundo Municipal de Meio Ambiente (FMMA) com a finalidade de financiar planos, programas, projetos e atividades, de caráter executivo ou de pesquisas científicas e tecnológicas, visando o uso racional e sustentado dos recursos naturais (Belém, 2005). A institucionalização dessa política representou um avanço da administração ao nortear legalmente as ações pertinentes à gestão ambiental do município de Belém.

Posteriormente, no Plano de Desenvolvimento Urbano (PDU) de 2008, a política municipal de meio ambiente foi sistematizada, integrando-a diretamente com a política urbana, na busca de promover a adequação das ações do poder PÚBLICO municipal e das coletividades municipais no desenvolvimento de suas atividades socioeconômicas com equilíbrio ambiental (Belém, 2008). Com efeito, o PDU veio nortear o direcionamento das ações pertinentes à política urbana e ambiental de Belém que, inclusive, passou a considerar as especificidades de cada área.
Tanto a Lei n. 8.489/05 que instituiu a Política Municipal de Meio Ambiente, o SISEMMA e o FMMA, quanto o PDU 2008 fornecem princípios e diretrizes para a gestão ambiental da cidade e dos parques urbanos. Porém, as ações de governança desenvolvidas pela administração municipal no período de 2005 a 2012 não propiciou a participação efetiva dos atores urbanos, particularmente no que diz respeito às ações pertinentes à gestão dos parques urbanos e, dentre estes, o do Parque Ecológico do Município de Belém Gunnar Vingren (PEGV).

De fato, para que a participação passe a fazer parte da concepção de governança relacionada à ideia de gestão do desenvolvimento compartilhada entre o Estado e a sociedade civil, torna-se imprescindível abordar os processos e mecanismos norteadores da participação para a gestão ambiental de parques (Vasconcellos \& Aranha, 2009a).

Nesse contexto, dentre os processos e mecanismos norteadores da participação dos atores sociais na condução da política ambiental do parque, destacase o Conselho Gestor do PEGV, que possui caráter consultivo. A gestão do parque utiliza o seu conselho como um instrumento para promover a governança e fomentar a participação dos atores sociais nas ações da gestão da área verde, incluindo os parques urbanos, seguindo as diretrizes do SNUC 2000. Como colocado anteriormente, o conselho é formado por 20 entidades, sendo 10 entidades representantes da sociedade civil organizada e 10 representantes de entidades públicas, conforme descrito no Quadro 1.

Tomando-se como referência a análise das atas de reuniões do Conselho Gestor do PEGV, a presença e participação dos membros nas primeiras reuniões variaram entre $60 \%$ a $70 \%$. Posteriormente, a partir

Quadro 1 - Instituicịoes representantes do Conselho Gestor do PEGV

INSTITUICÕES PÚBLICAS

Secretaria Municipal de Meio Ambiente (SEMMA)

Secretaria Municipal de Educação (SEMEC)

Companhia de Turismo de Belém (BELEMTUR)

Empresa Brasileira de Pesquisa Agropecuária (EMBRAPA)

Universidade Federal Rural da Amazônia (UFRA)

Museu Paraense Emilio Goeldi (MPEG)

Secretaria Estadual de Meio Ambiente (SEMA)

Batalhão de Polícia Ambiental (BPA)

Conselho Regional de Engenharia, Arquitetura e Agronomia do Pará (CREA/PA)

Marinha do Brasil

\section{SOCIEDADE CIVIL}

Associaç̃ão de Moradores dos Conjuntos Médici I e II (AMME)

Associaç̃o Sócio Cultural Bela Vista (ASCBV)

Associação Comunitária do Conjunto Residencial Euclides Figueiredo (ACCEF)

Associação de Moradores do Conjunto Ipuan (AMCI)

Associação de Moradores do Conjunto Mendara (ACM)

Associaç̃ão de Moradores do Conjunto Marex (AMCM)

Associaç̃o de Moradores do Conjunto Pedro Álvares Cabral (ACPAC)

Centro Comunitário Santos Dumont (CCSD)

Centro Comunitário União (CCU)

Sociedade de Preservaç̃o dos Recursos Naturais da Amazônia (SOPREN)

Fonte: Belém, 2010 
de 2011, a frequência e a participação dos membros nas reuniões do conselho reduziram para menos de 30\%. E, ainda, há o aparente desinteresse das comunidades do entorno do PEGV em participar das discussões concernentes à implementação do parque tendo em vista que a relação de proximidade entre gestores do governo municipal e as comunidades está enfraquecida devido aos divergentes interesses emanados dessa relação. Esse quadro é reflexo do modelo de gestão ambiental implantado em Belém desde 2005, cujas ações são baseadas em diagnósticos, relatórios técnicos e levantamentos estatísticos, em geral analisados nos gabinetes dos órgãos da administração direta e indireta. Desde esse período que a população não participa de forma direta nas tomadas de decisões no âmbito municipal, distanciando-se do pressuposto da "Boa Governança".

"Boa Governança" é conseguida por meio da articulação inteligente e equilibrada do conjunto dos atores interessados no desenvolvimento de um território, os chamados stakeholders (Sachs et al., 2010). É uma gestão que procura responder ou corresponder aos interesses que diferentes coletividades, ao serem empoderadas, manifestam por meio da participação social. A Boa Governança pressupõe sistemas mais democráticos, na linha da governança participativa, além da ampla transparência dos processos. A eficiência é medida no processo em que se dá a gestão e não só no resultado. É a diferença entre a eficiência autoritária por cima e a eficiência democrática pela base (Sachs et al., 2010). Pode-se inferir que a governança participativa constitui-se, então, em um instrumento de desenvolvimento urbano orientada pela conformação do espaço público ampliado e pela participação dos atores na forma de decisão e controle dos interesses sociais.

Os movimentos de gestão acima apresentados mostram que a experiência de governança urbana de Belém e seus diferentes modelos influenciam diretamente na relação entre o governo municipal e as coletividades da cidade. A forma de gestão do PEGV é, por conseguinte, apenas uma expressão do modelo democrático-participativo entre 1997 e 2004 e do modelo burocrático-centralizador que é predominante antes e após esse período.

\section{As convergências e divergências de interesses entre os atores sociais}

Sob a óptica da teoria dos stakeholders, a gestão baseada na participação social deve dar especial atenção aos atores sociais mais importantes, tanto àqueles que atuam no estabelecimento das ações gerenciais, quanto àqueles que agem nas políticas gerais e realizam tomadas de decisão (Donaldson \& Preston, 1995). A teoria dos stakeholders permite entender os interesses, convergências e divergências entre os atores sociais nas formas de pensar e agir que intrinsecamente se relacionam com o processo de implementação de um parque, a exemplo do PEGV. A teoria possui suas raízes na sociologia, no comportamento organizacional e na política de interesses de determinados grupos (Silveira et al., 2005).

Reed et al., (2009) discutem a base teórica, normativa e instrumental da teoria de stakeholders $\mathrm{e}$ propõem uma tipologia de análise da parte interessada a partir de métodos para: identificar stakeholders; diferenciar esses atores sociais, categorizandoos (trade-offs); e verificar relacionamentos de investigação entre os mesmos. Nesse contexto, os atores primários são definidos como sendo os stakeholders que possuem maior relevância na rede de relações entre atores; os atores secundários são aqueles com média importância; e os atores externos são definidos como os que possuem menor importância na rede de relações entre os atores que se relacionam e/ou influenciam a dinâmica cotidiana do parque urbano.

A partir da proposição de Reed et al., (2009), categorizaram-se os trade-offs que se relacionam direta e indiretamente com o PEGV (Quadro 2).

Na perspectiva da preservação dos recursos naturais do parque no ambiente urbano, o gestor do parque e presidente do Conselho Consultivo do PEGV enfatiza que proteger o parque é importante por dois principais motivos: o primeiro consiste na preservação de área verde em núcleo urbano e o segundo se caracteriza pelos benefícios dessa preservação, que são a amenização do calor, a infiltração da água da chuva, a possibilidade de educação ambiental que o parque proporciona e a conservação da área verde para a manutenção de ar puro, especialmente para as pessoas que moram nas proximidades do PEGV ou trafegam pela Avenida Centenário. 
Quadro 2 - Categorização dos trade-offs

\begin{tabular}{lll}
\hline \multicolumn{1}{c}{ Primários } & \multicolumn{1}{c}{ Secundários } \\
\hline 1. Gestor do PEGV & 5. Guarda Municipal (GBEL) & \multicolumn{1}{c}{ Externos } \\
2. Comunidade do entorno (moradores dos conjuntos & 6. Usuários do PEGV & 9. Instituições religiosas \\
habitacionais Médici e Bela Vista) & 7. Estação de Tratamento - & (Assembleia de Deus) \\
3. Conselho Gestor do PEGV & COSANPA/Invasão Água Cristal) & 10. Empresas públicas e privadas \\
4. Instituições de ensino e pesquisa & 8. NGTM/PA & 11. ONGs \\
\hline
\end{tabular}

Fonte: Adaptado de Carmona et al. (2009); elaboraç̃ão dos autores.

Se pelo lado do governo municipal há um entendimento amplo da importância do parque, que perpassa de funções ambientais a aspectos sociais e educacionais, pelo lado da sociedade civil a importância dada ao parque é unicamente de preservação dos recursos naturais. Poucos têm a concepção de parque como uma área verde inserida em um mosaico de unidades de conservação de uso indireto. Todavia, os entrevistados percebem o parque, também, como espaço de lazer e recreação. Provavelmente essa última percepção está relacionada à falta de espaços de lazer para as comunidades do entorno do parque. Essa confusão de interpretação pode explicar as posições divergentes entre os atores sociais na forma como lidar com o parque e, consequentemente, no seu engajamento no processo de gestão dele. Os trechos de entrevistas que seguem expressam as diferentes abordagens interpretativas entre os stakeholders primários e as posições divergentes que estes apresentam. Certamente essas divergências de entendimento explicam o porquê da baixa demanda para uso do parque por parte das comunidades de seu entorno. Se por um lado as comunidades adjacentes foram atores fundamentais para criação do parque, por outro lado eles não têm sido ativos o suficiente para provocar o aumento da participação dos membros do conselho nas reuniões. A participação dos conselheiros nas reuniões, como dito anteriormente, se reduziu para menos de $30 \%$.

[...] além da beleza e da conscientização ecológica, a área representa uma forma de lazer para todos que vivem em nossa cidade e principalmente para as comunidades carentes do redor [...] precisamos de recursos para poder implantar formas seguras de uso, promessas existem mas estamos buscando de fato que isto aconteça $[\ldots]^{6}$.

[...] o parque tem um valor ambiental para a formação da consciência ambiental e preservação desde que a comunidade tenha acesso, no sentido de conhecer o espaço [...] a escola tem buscado esse contato. A escola visita todos os anos o parque com turmas de $2^{\underline{a}}, 3^{\underline{a}} \mathrm{e}$ 4 a séries do ensino fundamental, com alunos na faixa etária de 7 a 14 anos [...]

Atores engajados no processo de participação para a implementação da gestão do parque via Conselho Gestor são, em geral, conscientes de que o conselho é um espaço de conflito por poder, seja de ordem política, seja de caráter institucional e/ou social. Representantes do governo e membros da sociedade civil no Conselho Gestor usualmente indicam em seus relatos que apesar de haver participação nas ações do conselho, há claros sinais de conflitos e divergências de interesses entre os stakeholders. De fato, os discursos dos atores mostram que há muitos momentos em que estão em lados opostos:

[...] as autoridades devem se despojar das vaidades pessoais; tem que haver integração entre governo e sociedade, pois durante o governo do Edmilson Rodrigues havia participação da comunidade, principalmente as escolas - tanto públicas quanto particulares participavam dos projetos de educação ambiental. Havia uma equipe interdisciplinar com técnicos da UFRA que desenvolviam projetos de educação ambiental junto à comunidade

\footnotetext{
6 Membro da ACCEF no Conselho Gestor do PEGV. Entrevista realizada em jan. 2012.

7 Orientadora educacional da EEEF Profa. Leonor Nogueira. Entrevista realizada em jan. 2012.
} 
[...] atualmente a grande dificuldade de participação da comunidade no parque consiste na rotatividade dos moradores, pois a maioria dos moradores do entorno não conhece o parque $[. . .]^{8 . "}$

[...] o parque está restrito, pois a comunidade não é convidada para participar da dinâmica do parque. Quando há visita programada pela escola, não há pessoal qualificado para receber a escola, apresentar o parque (fauna e flora). A comunidade de modo geral não está inserida $[. . .]^{9}$.

Para que a participação passe a fazer parte da concepção de governança ambiental (Vasconcellos et al., 2009b) do parque, uma interação positiva entre os diversos atores sociais que se relacionam com o PEGV é necessária, especialmente com as comunidades que vivem no entorno dessa área. No que diz respeito à interação entre os gestores do PEGV e as comunidades, as divergências aparecem em vários discursos:

[...] existe um bom diálogo entre todos e principalmente vontade da parte da prefeitura em concretizar este sonho; mas o que prevalece são pensamentos e vontades diferentes, estamos trabalhando para que isso possa ser superado brevemente $[\ldots]^{10}$.

"[...] a participação acontece devido a muitos fatores, por exemplo pela diversificação dos locais de reunião, onde são visitadas as comunidades participantes, dando a oportunidade de todos conhecerem os locais de cada uma e suas necessidades e se aprimora dando a cada comunidade a oportunidade de se expressar e exigir que suas necessidades sejam atendidas $[. . .]^{11 . "}$

\footnotetext{
8 Membro da SOPREN no Conselho Gestor do PEGV e ex-presidente da AMME. Entrevista realizada em jan. 2012.

9 Orientadora educacional da EEEF Profa. Leonor Nogueira. Entrevista realizada em jan. 2012.

${ }^{10}$ Membro da ACCEF no Conselho Gestor do PEGV. Entrevista realizada em jan. 2012.

${ }^{11}$ Funcionário público, membro da ASCBV no Conselho Gestor do PEGV. Entrevista realizada em jan. 2012.
}

De fato, há um reconhecimento de que os atores sociais não conseguem encontrar consensos mínimos para a gestão do parque, sobretudo porque não há participação, colaboração e abertura ao diálogo entre os stakeholders, sejam eles primários, secundários ou terciários:

[...] não há um relacionamento mútuo entre escola e parque para aproveitar o espaço nas práticas pedagógicas/atividades curriculares (educação ambiental, conhecimento da fauna e flora, etc.) [... $]^{12}$.

[...] a gestão precisa ser participativa, colaborativa. Não há participação, pois a escola nunca foi procurada para interagir com a gestão do parque. 0 espaço está ocioso, deve ter finalidade para a comunidade [...] precisa melhorar o acesso e a ausência de pessoal. [... $]^{13}$.

Na concepção de Coelho et al., (2006), o ideário da participação social promete a emergência, a partir do diálogo entre diferentes interesses, de novas coalizões capazes de pactuar um projeto comum que leve à dinamização e ao desenvolvimento (Coelho et al., 2006). A participação favorece que a sociedade civil se expresse em relação aos seus interesses e demandas, assim como acompanhe a utilização de recursos públicos e o cumprimento às leis e aos direitos. De modo geral, a governança participativa constitui-se em um instrumento norteador de mediação dos interesses e de disputa de poder entre os atores sociais que atuam direta e indiretamente na dinâmica cotidiana de uma área protegida. Entretanto, o que os discursos dos atores nos mostram é uma distância na busca de conciliação dos diversos interesses existentes. Isto se dá, sobretudo, em função da forma como o governo concebe o parque e age em sua gestão. A atual gestão municipal desconsidera que boa parte das divergências entre os stakeholders se vincula à forma como interferiu no parque e desestruturou todo o espaço adjacente onde o PEGV está instalado.

No que concerne aos interesses originados pela intervenção do Projeto Ação Metrópole, destacase que, embora a proposta do traçado da Avenida

\footnotetext{
${ }^{12}$ Diretor pedagógico da EEEFM Profa. Hilda Vieira. Entrevista realizada em jan. 2012.

${ }^{13}$ Orientadora educacional da EEEF Profa. Leonor Nogueira. Entrevista realizada em jan. 2012.
} 
Centenário tenha minimizado a perda de cobertura vegetal do PEGV, a degradação ambiental do parque foi elevada e contribuiu para intensificação das divergências entre os atores. Por exemplo, a decisão final foi norteada pela prevalência do interesse público sobre os interesses dos moradores do Conjunto Habitacional Bela Vista (Dias, 2010).

Nesse aspecto, as entrevistas realizadas com moradores do Conjunto Habitacional Bela Vista mostram o descontentamento com os gestores públicos em consequência da obra da avenida, o que indica o apartamento da comunidade de seu entorno no processo de planejamento da área:

[...] sofremos uma truculenta destruição da mata nativa, pertencente ao Conjunto Bela Vista para a passagem de uma via, necessária sim, mas que tinha outras alternativas, que não fosse a invasão de área privada. Estamos doentes [...] agora nos chamam para fazer parte do Conselho do Parque, não fomos ouvidos no momento das obras, fomos banidos, tratados com arrogância pelos construtores [...] para mim o parque faz parte de um processo de negociação que só tem trazido insegurança, poluição sonora, doenças, acidentes, engarrafamentos diários de carros, enfim intranquilidade. Muitas casas foram abaladas em suas estruturas, temos documentações legais. Muito alagamento, destruição do nosso patrimônio, construído com trabalho honesto [...] lamentável [...] ${ }^{14}$.

Segundo o presidente do Conselho Gestor do PEGV, o fórum se reuniu ordinariamente durante o primeiro semestre de 2011 apenas duas vezes. Nestas reuniões foram discutidas propostas de planejamento e implantação do regimento interno do PEGV, além da elaboração e implantação de um projeto para o uso público do parque que integra, inclusive, palestras sobre educação ambiental aos visitantes do local. No segundo semestre de 2011 houve novamente apenas duas reuniões do conselho. Nestas últimas reuniões foram abordados os problemas estruturais no Conjunto Bela Vista decorrentes da construção da Avenida Centenário. As demandas originadas pelos moradores do conjunto foram identificadas,

\footnotetext{
${ }^{14}$ Moradora do Conjunto Habitacional Bela Vista. Entrevista realizada em jan. 2012.
}

entretanto não foram levadas em consideração por questões burocrático-administrativas:

[...] temos total interesse em resolver os problemas estruturais da obra, porém estamos com dificuldade nesse sentido [...] através da conversa estamos tentando resolver tecnicamente, pois, na via judicial isso demandaria muito tempo [...] não há permuta uma vez que as construtoras já receberam todos os recursos financeiros [...] estamos tentando fazer com que as construtoras honrem o contrato $[. . .]^{15}$.

De toda ordem, os atores sociais têm tido foco na transformação da estrutura de organização do parque enquanto espaço para uso coletivo. Ao assumirem ativamente um papel na reformulação do espaço público, os atores sociais criaram novamente um ambiente político propício à implantação de políticas que possam contribuir para o fortalecimento dos mecanismos de desenvolvimento nos quais estão inseridos. Entretanto, isso não tem ocorrido em função da prevalência da burocracia sobre as demandas das coletividades locais. Assim, ainda que as expectativas de participação social existam, os interesses, as divergências e as limitações na resolução dos problemas estruturais prejudicam a efetiva participação dos atores na gestão do parque por via do Conselho Gestor.

Os parques urbanos são importantes locais para preservar as áreas verdes que ainda existem na cidade e, com essa preservação, contribuir para a manutenção ou melhoria da qualidade de vida das pessoas da cidade. Contudo há muitos desafios a serem perseguidos para uma efetiva governança ambiental desses espaços. Dentre todos os desafios, talvez o mais proeminente seja construir uma aliança de governança participativa entre os atores sociais, tendo em vista que a efetivação das instâncias de participação representa a democratização das ações de gestão ambiental nos parques urbanos.

\section{Considerações finais}

0 presente artigo buscou discutir as dificuldades e facilidades inerentes à implementação da gestão ambiental de parques urbanos. Focou-se nas relações estabelecidas entre os atores sociais que atuam de

\footnotetext{
${ }^{15}$ Coordenadora do Ação Metrópole. Reunião NGTM. Jan. 2012.
} 
forma direta e indireta na governança ambiental. 0 estudo apresenta três perspectivas conclusivas que são inerentes à gestão de parques urbanos, e em particular na gestão do PEGV.

Primeiro, o estudo mostra a importância dos movimentos sociais urbanos para a preservação das áreas verdes da cidade em busca da manutenção e/ou melhoria da qualidade de vida das pessoas que vivem na cidade. A pesquisa demonstrou que a criação do PEGV foi resultado dos movimentos sociais dos moradores dos Conjuntos Presidente Médici I e II que inclusive passaram a ser legalmente um dos principais atores para a gestão do parque via Conselho Gestor. Esses movimentos sociais foram uma reação às tentativas de invasão da área onde, posteriormente, se criou o PEGV. Todavia o estudo mostra, também, que à medida que os espaços institucionais vão se formalizando, os movimentos sociais perdem sua forma ativa de reivindicação na interação com os agentes do governo e estes passam a dominar o controle da área e fazer prevalecer seus projetos urbanísticos com baixo diálogo com as coletividades locais.

Segundo, o estudo aponta que a gestão ambiental dos parques urbanos depende fundamentalmente do ordenamento do seu próprio território e de seu entorno. Para isso, a demarcação exata da área e a divulgação dessa demarcação para as comunidades adjacentes ao parque e, também, da cidade como um todo, são essenciais para que a população se empodere do parque enquanto espaço de uso coletivo. Em áreas com território desordenado é elevada a possibilidade de pressão no uso do parque para outras finalidades e depredação de seus recursos naturais.

0 exemplo do PEGV nos mostra que o baixo empoderamento da população no uso do parque enquanto espaço público de uso coletivo facilitou a proposição de projetos urbanísticos por parte do poder público sem que houvesse um diálogo maior com as coletividades locais para definir as prioridades e formas de uso da área. Consequentemente, os projetos urbanísticos implementados pelo poder público dentro do parque não foram apropriados como ações para o bem coletivo e isso aumentou as possibilidades de invasão da área. 0 exemplo do PEGV mostra que a implantação de projetos urbanísticos aumentou a pressão sobre o uso do espaço aguçando as dificuldades para sua gestão. A intervenção dos dois significativos projetos governamentais, o Projeto da Macrodrenagem da Bacia do Una, em 1998, e o Projeto de Extensão da Avenida Centenário (Projeto Ação Metrópole), em 2010, contribuíram para o aumento da pressão sobre o parque, desmatamento, depredação dos recursos naturais primários e, assim, ampliação dos conflitos em função dos diferentes interesses dos atores urbanos.

Terceiro, o estudo demonstra que os modelos de gestão urbana da cidade influenciam no nível de participação dos atores sociais locais nas arenas de diálogo entre governo e sociedade civil (no caso específico do PEGV, o seu Conselho Gestor) e determina o nível de conciliação de interesses entre estes. É comum existir divergência de interesses entre atores sociais nos fóruns de participação, sejam eles conselhos, comitês ou de outras denominações; entretanto, essas divergências podem ser minimizadas se o modelo de gestão da cidade promover maior diálogo com as coletividades locais e, assim, considerar as suas demandas. No caso específico do PEGV, o estudo mostra que a participação e o maior diálogo entre governo e sociedade civil ocorreram entre 1997 e 2004 na gestão do prefeito Edmilson Rodrigues. Antes e após esse período houve predominância da gestão tecno-burocrática de prevalência dos projetos urbanísticos governamentais. Entende-se que essa prevalência está claramente vinculada ao modelo de gestão adotado nos diversos períodos de administração da cidade e, consequentemente, na gestão do PEGV. Assim, um grande desafio na gestão de parques urbanos é o de construção de uma aliança de governança participativa que priorize as coletividades locais.

Empiricamente o estudo identificou que a capacidade institucional para a gestão do PEGV avançou bastante com a criação da Política Municipal de Meio Ambiente, do Sistema Municipal de Meio Ambiente (SISEMMA) e do Fundo Municipal do Meio Ambiente; todavia, paradoxalmente, a capacidade organizacional do governo municipal é limitada em termos de recursos humanos e financeiros para a gestão de todo o sistema e do PEGV, em particular. Isso acaba por enfraquecer os espaços políticos e as arenas de participação que foram criados para o fortalecimento e desenvolvimento de ações coletivas favoráveis à implantação de políticas de desenvolvimento da cidade que tenham 
o foco ambiental. Sendo assim, a prevalência tecnoburocrática acabou por deixar em segundo plano a participação dos atores sociais no Conselho Gestor do PEGV. Isso demonstra que a criação de um conselho por si só não cria condições de "Boa Governança" e conciliação de interesses entre os stakeholders. É preciso ter, além de condições institucionais, capacidade organizacional para que a Boa Governança seja perseguida.

\section{Referências}

Belém (1991). Lei n. 7.539, de 19/11/1991. Cria o Parque Ecológico de Belém. Recuperado em 20 de fevereiro de 2010, de http://www.belem.pa.gov.br.

Belém. (1992). Projeto de saneamento para recuperação das baixadas de Belém: Bacia do Una, (Vol. 1). Belém: SEGEP/PMB. 268 p.

Belém. Dossiê de Candidatura - Belém/Pará/Brasil. (1999). Cidade Coordenadora e Sede do Secretariado Técnico do Grupo de Trabalho Gestão Participativa dos Rios Urbanos de Cidades da América Latina e Caribe. Belém: SEGEP/PMB. 82 p.

Belém. (2000). Parque ecológico do município de Belém: plano de manejo. Fase 1. Belém: FUNVERDE. 56 p. Relatório Técnico.

Belém. (2005). Lei n. 8.489, de 29 de dezembro de 2005. Institui a política municipal de meio ambiente e o SISEMMA do município de Belém. Recuperado em 20 de julho de 2011, de http://www.belem.pa.gov.br.

Belém. (2008, 31 de julho). Plano Diretor de Belém. Lei $n^{\circ}$ 8.655/08. Belém: Diário Oficial [do] Município n. 11.189. Recuperado em 20 de fevereiro de 2010, de http://www. belem.pa.gov.br.

Belém. (2010). Portaria n. 110, de 29 de setembro de 2010. Cria o Conselho Consultivo PEGV. Recuperado em 20 de julho de 2011, de http://www.belem.pa.gov.br.

Brasil. Ministério do Meio Ambiente (2000, 19 de julho). Lei n. 9.985, de 18 de Julho de 2000. Sistema Nacional de Unidades de Conservação da Natureza - SNUC. Diário Oficial [da] República Federativa do Brasil.

Broch, S. A. O., Bursztyn, M. A. A., \& Souza, P. R. (2000). Em busca da governança das águas para o desenvolvimento sustentável na região da Bacia Hidrográfica do Rio Apa.
In Anais do II Colóquio Internacional de Desenvolvimento Local. Bahia.

Cardoso, S. L. C. (2012). Subsídios à gestão de parques urbanos: o caso do Parque Ecológico do Município de Belém Gunnar Vingren (PEGV). (Dissertação de mestrado em Desenvolvimento Local e dos Recursos Naturais). Universidade Federal do Pará, Núcleo Meio Ambiente, Belém.

Carmona, V. C., Boaventura, J. M. G., Costa, B. K., \& Vieira, S. F. A. (2009). Análise de Stakeholders aplicada em órgãos públicos: o caso da Secretaria de Estado do Turismo do Paraná (SETU). Paraná. Recuperado em 20 de março de 2011, de http//:www.ead.fea.usp.br.

Chiesura, A. (2004). The role of urban parks for the sustainable city. Landscape and Urban Planning, 68(1), 129-138. http://dx.doi.org/10.1016/j. landurbplan.2003.08.003.

Companhia de Desenvolvimento e Administração da Área Metropolitana de Belém - CODEM. (2012). Levantamento aerofotogramétrico de Belém - 1998. Belém.

Coelho, V.S., Favareto, A., Galvanezze, C., \& Menino, F. (2006). Fóruns Participativos e Desenvolvimento Territorial no Vale do Ribeira (Brasil). In Seminário Internacional Territórios Rurales em Movimiento: movimientos sociales, actores e instituciones Del desarrollo territorial rural. Santiago do Chile.

Dias, S. V. (2010). Licenciamento ambiental: as sobreposições das ações entre os três níveis de governo - o caso do Estado do Pará. (Dissertação de mestrado em Gestão dos Recursos Naturais e Desenvolvimento Local na Amazônia). Universidade Federal do Pará, Núcleo de Meio Ambiente, Belém.

Donaldson, T., \& Preston, L. E. (1995). The stakeholder theory of the corporation: concepts, evidence, and implications. Academy of Management Review, 20(1), 65-91.

Evans, P. (1997). Government action, social capital and development: reviewing the evidence on synergy. In Evans, P. State-society synergy: government and social capital in development. Berkeley: University of California at Berkeley.

Farias, R. S. S. (2004). Planejamento e gestão participativos em Belém-Pa: o Congresso da Cidade (2001-2004). (Dissertação de Mestrado em Planejamento Urbano e Regional). Universidade Federal do Rio Grande do Sul, Faculdade de Arquitetura, Porto Alegre. 
Faria, H. M. (1998). Parques urbanos e áreas de preservação permanente: elementos estruturadores da sustentabilidade urbana. Itajubá: Centro Universitário de Itajubá/Fundação de Ensino e Pesquisa de Itajubá. Recuperado em 14 de agosto de 2011, em http://www.geo.ufv.br/simposio/ simposio/trabalhos/trabalhos_completos/eixo11/039. pdf.

Ferreira, A. D. (2006). Efeitos positivos gerados pelos parques urbanos; o caso do passeio público da cidade do Rio de Janeiro. (Dissertação de mestrado do Curso de Pósgraduação em Ciência Ambiental - PGCA). Universidade Federal Fluminense, Rio de Janeiro.

Kaplan, R. (1983). The analysis of perception via preference: a strategy for studying how the environment is experienced. Landscape and Urban Planning, (12), $161-176$.

Kliass, R. G. (1993). Os parques urbanos de São Paulo. São Paulo: Pini. 211 p.

Lau, M. C. (2008). Parque estadual Xixová-Japuí: análise do relacionamento com a população de entorno. (Monografia). Universidade Estadual Paulista, São Vicente.

Lima, A. E. M., \& Rocha, N. M. M. (2009). Dinâmica de parques urbanos em Fortaleza-CE: considerações sobre o parque Rio Branco. Recuperado em 1 de março de 2011, em http://www.anppas.org.br/Luciene/Silva.pdf.

Loures, L., Santos, R., \& Panagopoulos, T. (2007). Urban parks and sustainable city planning: the case of Portimão, Portugal. WSEAS Transactions on Environment and Development, 3(10), 171-180.

Macedo, S. S., \& Sakata, F. G. (2002). Parques urbanos no Brasil (Coleção Quapá). São Paulo: USP/Imprensa Oficial do Estado.

Maia, F. L. C. (2009). Reflexões sobre a política de gestão ambiental de Belém. In G. M. Vasconcellos \& E. Ladislau (Orgs.), O desafio político da sustentabilidade urbana: gestão sócio-ambiental de Belém. Belém: UFPA/NUMA/ EDUFPA. 179 p.

McCormack, G. R., Rock, M., Toohey, A. M., \& Hignell, D. (2010). Characteristics of urban parks associated with park use and physical activity: a review of qualitative research. Health \& Place, 16(4), 712-726. http://dx.doi. org/10.1016/j.healthplace.2010.03.003. PMid:20356780
Pará. Secretaria Especial de Projetos Estratégicos - SEPE. (2010). Projeto Ação Metrópole. Recuperado em 15 de março de 2010, em http://www.sepe.pa.gov.br.

Reed, M. S., Graves, A., Dandy, N., Posthumus, H., Hubacek, K., Morris, J., Prell, C., Quinn, C. H., \& Stringer, L. C. (2009). Who's in and why? A typology of stakeholder analysis methods for natural resource management. Journal of Environmental Management, 90(5), 19331949. http://dx.doi.org/10.1016/j.jenvman.2009.01.001. PMid:19231064</jrn>.

Rocha, I., \& Feitosa, M. (2012). Governança em Ong's: um ensaio teórico. In Anais do XII Colóquio sobre Poder Local Desenvolvimento e Gestão Social de Territórios. Salvador.

Rodrigues, A. L., \& Malo, M. C. (2006). Estruturas de governança e empreendedorismo coletivo: o caso dos doutores da alegria. Revista de Administração Contemporânea, 10(3). http://www.dx.doi.org. 10.1590.

Sachs, I., Lopes, C., \& Dowbor, L. (2010). Crises e oportunidades em tempos de mudanças. Economia Global e Gestão, 15(1), 133-154. Recuperado em 10 de janeiro de 2012, em http://www.scielo.oces.mctes.pt/pdf/egg/ v15n1/v15n1a08.pdf.

Scalise, W. (2002). Parques urbanos: evolução, projeto, funções e uso. Revista Assentamentos Humanos, 4(1), 17-24.

Silva, L. J. M. (2003a). Parques urbanos: a natureza na cidade: uma análise da percepção dos atores urbanos. (Dissertação de mestrado em Desenvolvimento Sustentado). UNB Centro de Desenvolvimento Sustentado, Brasília.

Silva, L. J. M. (2003b). O estudo da percepção em espaços urbanos preservados. Centro de Desenvolvimento Sustentável/Ministério de Ciência e Tecnologia.

Silva, L. E. L. (2008). Gestão de áreas protegidas: análise de fatores ambientais impactados no PEMB. (Monografia de Especialização em Gestão Ambiental). Universidade Federal do Pará, Núcleo de Meio Ambiente, Belém.

Silveira, A. M., Yoshinaga, C. M., \& Borba, P. R. F. (2005). Crítica à teoria dos stakeholders como função-objetivo corporativa. Cadernos de Pesquisa em Administração, 12(1), 33-42.

Tendler, J. (1997). Good governance in the tropics. Baltimore: University Press. 221 p.

Terra, C. G. (2000). O jardim no Brasil do século XXI: Glaziou revisitado (2. ed.). Rio de Janeiro: EBA/UFRJ. 240 p. 
Tratalos, J., Fuller, R. A., Warren, P. H., Davies, R. G., \& Gaston, K. J. (2007). Urban form, biodiversity potential and ecosystem services. Landscape and Urban Planning, 83(4), 308-317. http://dx.doi.org/10.1016/j. landurbplan.2007.05.003.

Ulrich, R. S. (1984). View through a window may influence recovery from surgery. Science, (224), 420-421.

Vainer, A. G. (2010). Conflitos ambientais em evidência na criação e manejo de um parque nacional: o caso do Parque Nacional da Restinga de Jurubatiba. In Anais do XIX Encontro Nacional do CONPEDI. Fortaleza. Recuperado em 2 de agosto de 2011, em http://www.conpedi.org.br/ arquivos/anais/fortaleza.pdf.
Vasconcellos, A. M., \& Aranha, J. (2009a). Gestão participativa para conservação de parques ambientais: o Parque Estadual de Belém e a comunidades do entorno. In M. Vasconcellos, G. M. Rocha \& E. Ladislau (Orgs.), $O$ desafio político da sustentabilidade urbana: gestão sócioambiental de Belém. Belém: UFPA/NUMA/EDUFPA. 179 p.

Vasconcellos, M., Vasconcellos, A. M., \& Souza, C. A. (2009b). Participação e governança urbana. In M. Vasconcellos, G. M. Rocha \& E. Ladislau (Orgs.), O desafio político da sustentabilidade urbana: gestão sócio-ambiental de Belém. Belém: UFPA/NUMA/EDUFPA. 179 p.

Recebido: Abr. 16, 2014

Aprovado: Set. 9, 2014 